\title{
Strong Convergence to a Solution of a Variational Inequality Problem in Banach Spaces
}

\author{
Yasunori Kimura $^{1}$ and Kazuhide Nakajo ${ }^{2}$ \\ ${ }^{1}$ Department of Information Science, Toho University, Miyama, Funabashi, Chiba 274-8510, Japan \\ ${ }^{2}$ Sundai Preparatory School, Surugadai, Kanda, Chiyoda-ku, Tokyo 101-8313, Japan \\ Correspondence should be addressed to Yasunori Kimura; yasunori@is.sci.toho-u.ac.jp
}

Received 22 January 2014; Accepted 14 May 2014; Published 9 June 2014

Academic Editor: Luigi Muglia

Copyright (c) 2014 Y. Kimura and K. Nakajo. This is an open access article distributed under the Creative Commons Attribution License, which permits unrestricted use, distribution, and reproduction in any medium, provided the original work is properly cited.

We consider the variational inequality problem for a family of operators of a nonempty closed convex subset of a 2-uniformly convex Banach space with a uniformly Gâteaux differentiable norm, into its dual space. We assume some properties for the operators and get strong convergence to a common solution to the variational inequality problem by the hybrid method proposed by Haugazeau. Using these results, we obtain several results for the variational inequality problem and the proximal point algorithm.

\section{Introduction}

Let $\mathbb{N}$ and $\mathbb{R}$ be the set of all positive integers and the set of all real numbers, respectively. Throughout this paper, $E$ is a real Banach space with norm $\|\cdot\|$ and $E^{*}$ is the dual of $E$. For $x \in E$ and $x^{*} \in E^{*}$, let $\left\langle x, x^{*}\right\rangle$ be the value of $x^{*}$ at $x$. Suppose that $C$ is a nonempty closed convex subset of $E$ and $A$ is a monotone operator of $C$ into $E^{*}$; that is, $\langle x-y, A x-A y\rangle \geq 0$ holds for all $x, y \in C$. Then, we consider the variational inequality problem [1], that is, the problem of finding an element $z \in C$ such that

$$
\langle x-z, A z\rangle \geq 0 \quad \forall x \in C .
$$

The set of all solutions to the variational inequality problem for $A$ is denoted by $\operatorname{VI}(C, A)$. For $\alpha>0$, we say that $A$ is $\alpha$ inverse strongly monotone $[2-5]$ if

$$
\langle x-y, A x-A y\rangle \geq \alpha\|A x-A y\|^{2} \quad \forall x, y \in C .
$$

Haugazeau [6] introduced a sequence $\left\{x_{n}\right\}$ generated by the hybrid method by the following way. Let $\left\{T_{n}\right\}$ be a family of mappings of a real Hilbert space $H$ into itself with $\bigcap_{n=0}^{\infty} F\left(T_{n}\right) \neq \emptyset$, where $F\left(T_{n}\right)$ is the set of all fixed points of $T_{n}$. Let $\left\{x_{n}\right\}$ be a sequence generated by

$$
\begin{aligned}
x_{1} & =x \in H, \\
y_{n} & =T_{n} x_{n}, \\
C_{n} & =\left\{z \in H:\left\langle x_{n}-y_{n}, y_{n}-z\right\rangle \geq 0\right\}, \\
Q_{n} & =\left\{z \in H:\left\langle x_{n}-z, x-x_{n}\right\rangle \geq 0\right\}, \\
x_{n+1} & =P_{C_{n} \cap Q_{n}}(x)
\end{aligned}
$$

for each $n \in \mathbb{N}$, where $P_{C_{n} \cap Q_{n}}$ is the metric projection of $H$ onto $C_{n} \cap Q_{n}$. He proved a strong convergence theorem when $T_{n}=P_{(n \bmod m)+1}$ for every $n \in \mathbb{N}$, where $P_{i}$ is the metric projection of $H$ onto a nonempty closed convex subset $C_{i}$ of $H$ for each $i=1,2, \ldots, m$ with $\bigcap_{i=1}^{m} C_{i} \neq \emptyset$. Later, Solodov and Svaiter [7], Bauschke and Combettes [8], Nakajo and Takahashi [9], and many researchers studied the hybrid method in a real Hilbert space. In a real Banach space, Kamimura and Takahashi [10], Ohsawa and Takahashi [11], Kohsaka and Takahashi [12], Matsushita and Takahashi [13], Matsushita et al. [14], Nakajo et al. [15], and several researchers studied the hybrid method. 
In a real Hilbert space $H$, Iiduka et al. [16] considered a sequence $\left\{x_{n}\right\}$ generated by the following hybrid method:

$$
\begin{aligned}
x_{1} & =x \in C, \\
y_{n} & =P_{C}\left(x_{n}-\lambda_{n} A x_{n}\right), \\
C_{n} & =\left\{z \in C:\left\|y_{n}-z\right\| \leq\left\|x_{n}-z\right\|\right\}, \\
Q_{n} & =\left\{z \in C:\left\langle x_{n}-z, x-x_{n}\right\rangle \geq 0\right\}, \\
x_{n+1} & =P_{C_{n} \cap Q_{n}} x
\end{aligned}
$$

for each $n \in \mathbb{N}$, where $A$ is an $\alpha$-inverse strongly monotone operator of $C$ into $H$ with $\operatorname{VI}(C, A) \neq \emptyset, P_{C}$ is the metric projection of $H$ onto a nonempty closed convex subset $C$ of $H$, and $\left\{\lambda_{n}\right\} \subset[0,2 \alpha]$. They proved that $\left\{x_{n}\right\}$ converges strongly to $P_{\mathrm{VI}(C, A)} x$; see also $[17,18]$. In a 2-uniformly convex and uniformly smooth Banach space $E$, Iiduka and Takahashi [19] proved the following.

Theorem 1 (Iiduka and Takahashi [19]). Let $A$ be an $\alpha$-inverse strongly monotone operator of $E$ into $E^{*}$ with $A^{-1} 0 \neq \emptyset$ and $\left\{\lambda_{n}\right\} \subset\left[a, c_{1} \alpha\right]$ for some $\left.a \in\right] 0, c_{1} \alpha\left[\right.$, where $c_{1}$ is a positive constant satisfying that $\|x+y\|^{2} \geq\|x\|^{2}+2\langle y, J x\rangle+c_{1}\|y\|^{2}$ for every $x, y \in E$. Let $\left\{x_{n}\right\}$ be a sequence generated by

$$
\begin{aligned}
x_{1} & =x \in E, \\
y_{n} & =J^{-1}\left(J x_{n}-\lambda_{n} A x_{n}\right), \\
C_{n} & =\left\{z \in E: \phi\left(z, y_{n}\right) \leq \phi\left(z, x_{n}\right)\right\}, \\
Q_{n} & =\left\{z \in E:\left\langle x_{n}-z, J x-J x_{n}\right\rangle \geq 0\right\}, \\
x_{n+1} & =\Pi_{C_{n} \cap Q_{n}} x
\end{aligned}
$$

for each $n \in \mathbb{N}$, where $\Pi_{C_{n} \cap Q_{n}}$ is the generalized projection of $E$ onto $C_{n} \cap Q_{n}$ and $\phi(x, y)=\|x\|^{2}-2\langle x, J y\rangle+\|y\|^{2}$ for $x, y \in E$. Then, $\left\{x_{n}\right\}$ converges strongly to $\Pi_{A^{-1} 0} x$.

Motivated by [19], we propose a new family of operators and prove strong convergence theorems of the sequence generated by these mappings. Using these results, we get several additional results for the problem of variational inequalities and the proximal point algorithm.

\section{Preliminaries}

Throughout this paper, we write $x_{n} \rightarrow x$ to indicate that a sequence $\left\{x_{n}\right\}$ converges weakly to $x$ and $x_{n} \rightarrow x$ will symbolize strong convergence. We denote by $S_{E}$ the unit sphere of a Banach space $E$; that is, $S_{E}=\{x \in E:\|x\|=1\}$.

We define the modulus $\delta_{E}$ of convexity of $E$ as follows: $\delta_{E}$ is a function of $[0,2]$ into $[0,1]$ such that

$$
\delta_{E}(\epsilon)=\inf \left\{1-\frac{\|x+y\|}{2}: x, y \in S_{E},\|x-y\| \geq \epsilon\right\}
$$

for every $\epsilon \in[0,2]$. $E$ is said to be uniformly convex if $\delta_{E}(\epsilon)>0$ for each $\epsilon>0$. Let $p>1$. $E$ is said to be $p$-uniformly convex if there exists a constant $c>0$ such that $\delta_{E}(\epsilon) \geq c \epsilon^{p}$ for every $\epsilon \in[0,2]$. It is obvious that a $p$-uniformly convex Banach space is uniformly convex. $E$ is said to be strictly convex if $\|x+y\| / 2<1$ for all $x, y \in S_{E}$ with $x \neq y$. We know that a uniformly convex Banach space is strictly convex and reflexive. The duality mapping $J: E \rightarrow 2^{E^{*}}$ of $E$ is defined by

$$
J(x)=\left\{f \in E^{*}:\langle x, f\rangle=\|x\|^{2}=\|f\|^{2}\right\}
$$

for every $x \in E$. It is also known that if $E$ is strictly convex and reflexive, then the duality mapping $J$ of $E$ is bijective and $J^{-1}: E^{*} \rightarrow 2^{E}$ is the duality mapping of $E^{*} . E$ is said to be smooth if the limit

$$
\lim _{t \rightarrow 0} \frac{\|x+t y\|-\|x\|}{t}
$$

exists for every $x, y \in S_{E}$. The norm of $E$ is said to be uniformly Gâteaux differentiable if, for each $y \in S_{E}$, the limit (8) is attained uniformly for $x \in S_{E}$. $E$ is said to be uniformly smooth if the limit (8) is attained uniformly for $(x, y) \epsilon$ $S_{E} \times S_{E}$. We know that the duality mapping $J$ of $E$ is singlevalued if and only if $E$ is smooth. It is also known that if $E$ is uniformly smooth, then the duality mapping $J$ is uniformly continuous on bounded subsets of $E$ and if the norm of $E$ is uniformly Gâteaux differentiable, then $J$ is norm-to-weak ${ }^{*}$ uniformly continuous on bounded subsets of $E$; see [20, 21] for more details. The following is proved by $\mathrm{Xu}$ [22]; see also [23].

Theorem 2 (Xu [22]). Let E be a smooth Banach space. Then, the following are equivalent.

(i) E is 2-uniformly convex.

(ii) There exists a constant $c_{1}>0$ such that $\|x+y\|^{2} \geq$ $\|x\|^{2}+2\langle y, J x\rangle+c_{1}\|y\|^{2}$ holds for each $x, y \in E$.

Remark 3. In the case where $E$ is a real Hilbert space, $J$ is the identity mapping and we can choose $c_{1}=1$.

Let $E$ be a smooth Banach space. The function $\phi: E \times E \rightarrow$ $\mathbb{R}$ is defined by

$$
\phi(y, x)=\|y\|^{2}-2\langle y, J x\rangle+\|x\|^{2}
$$

for every $x, y \in E$. It is obvious that $(\|y\|-\|x\|)^{2} \leq \phi(y, x) \leq$ $(\|y\|+\|x\|)^{2}$ for each $x, y \in E$ and $\phi(z, x)+\phi(x, y)=\phi(z, y)+$ $2\langle x-z, J x-J y\rangle$ for all $x, y, z \in E$. It is also known that if $E$ is strictly convex and smooth, then, for $x, y \in E, \phi(y, x)=0$ if and only if $x=y$; see also [13]. We have the following result from Theorem 2 .

Lemma 4. Let $E$ be a 2-uniformly convex and smooth Banach space. Then, for each $x, y \in E, \phi(x, y) \geq c_{1}\|x-y\|^{2}$ holds, where $c_{1}$ is a constant in Theorem 2.

Proof. Let $x, y \in E$. By Theorem 2, we have

$$
\phi(x, y)=\|x\|^{2}-\|y\|^{2}-2\langle x-y, J y\rangle \geq c_{1}\|x-y\|^{2},
$$

which is the desired result. 
Let $C$ be a nonempty closed convex subset of a strictly convex, reflexive, and smooth Banach space $E$ and let $x \in E$. Then, there exists a unique element $y_{0} \in C$ such that

$$
\phi\left(y_{0}, x\right)=\inf _{y \in C} \phi(y, x) .
$$

We denote $y_{0}$ by $\Pi_{C} x$ and call $\Pi_{C}$ the generalized projection of $E$ onto $C$; see $[10,24,25]$. We have the following wellknown results $[10,24,25]$ for the generalized projection.

Lemma 5. Let $C$ be a nonempty convex subset of a smooth Banach space $E, x \in E$, and $y_{0} \in C$. Then, $\phi\left(y_{0}, x\right)=$ $\inf _{y \in C} \phi(y, x)$ if and only if $\left\langle y_{0}-z, J x-J y_{0}\right\rangle \geq 0$ for all $z \in C$.

Let $C$ be a nonempty closed convex subset of a strictly convex and reflexive Banach space $E$ and let $x \in E$. Then, there exists a unique element $y_{0} \in C$ such that $\left\|y_{0}-x\right\|=$ $\inf _{y \in C}\|y-x\|$. Putting $y_{0}=P_{C} x$, we call $P_{C}$ the metric projection of $E$ onto $C$; see [26]. We have the following result for the metric projection; see [20] for more details.

Lemma 6. Let $C$ be a nonempty closed convex subset of a strictly convex, reflexive, and smooth Banach space $E, x \in E$, and $y_{0} \in C$. Then, $y_{0}=P_{C} x$ if and only if $\left\langle y_{0}-z, J\left(x-y_{0}\right)\right\rangle \geq 0$ for all $z \in C$.

An operator $T: E \rightarrow 2^{E^{*}}$ is said to be monotone if $\langle x-$ $\left.y, x^{*}-y^{*}\right\rangle \geq 0$ for every $\left(x, x^{*}\right),\left(y, y^{*}\right) \in T$. Notice that we often identify a set-valued operator with its graph; $x^{*} \in T x$ if and only if $\left(x, x^{*}\right) \in T$.

A monotone operator $T \subset E \times E^{*}$ is said to be maximal if the graph of $T$ is not properly contained in the graph of any other monotone operator. It is easy to see that a monotone operator $T \subset E \times E^{*}$ is maximal if and only if, for $\left(u, u^{*}\right) \epsilon$ $E \times E^{*},\left\langle x-u, x^{*}-u^{*}\right\rangle \geq 0$ for every $\left(x, x^{*}\right) \in T$ implies that $\left(u, u^{*}\right) \in T$. We know the following result.

Theorem 7 (Rockafellar [27]; see also [28]). Let E be a strictly convex, reflexive, and smooth Banach space and let $T$ be a monotone operator of $E$ into $E^{*}$. Then, $T$ is maximal if and only if $R(J+r T)=E^{*}$ for all $r>0$, where $R(J+r T)$ is the range of $J+r T$.

From this fact, we also know that if $E$ is a strictly convex, reflexive, and smooth Banach space and $T$ is a maximal monotone operator of $E$ into $E^{*}$, then, for any $x \in E$ and $r>0$, there exists a unique element $x_{r} \in D(T)$ such that $J\left(x_{r}-x\right)+r T x_{r} \ni 0$, where $D(T)$ is the domain of $T$. We define $J_{r}: E \rightarrow E$ by $J_{r} x=x_{r}$ for every $x \in E$ and $r>0$, and such $J_{r}$ is called the resolvent of $T$; see [21,29] for more details.

\section{Main Results}

Let $C$ be a nonempty closed convex subset of a strictly convex, reflexive, and smooth Banach space $E$ and $\left\{A_{n}\right\}_{n \in \mathbb{N}}$ a family of operators of $C$ into $E^{*}$ satisfying the following:

(i) $F=\bigcap_{n=1}^{\infty} \operatorname{VI}\left(C, A_{n}\right) \neq \emptyset$; (ii) $\left\langle x-z, A_{n} x-A_{n} z\right\rangle \geq 0$ for all $n \in \mathbb{N}, x \in C$, and $z \in F$;

(iii) there exists a sequence $\left\{\alpha_{n}\right\}_{n \in \mathbb{N}}$ in $] 0, \infty$ [ such that $0<\liminf _{n \rightarrow \infty} \alpha_{n} \leq \limsup _{n \rightarrow \infty} \alpha_{n}<\infty$ and $\left\langle x-z, A_{n} x\right\rangle \geq \alpha_{n}\left\|A_{n} x-A_{n} z\right\|^{2}$ for every $n \in \mathbb{N}$, $x \in C$, and $z \in F$;

(iv) for all $z \in F, \sup _{n \in \mathbb{N}}\left\|A_{n} z\right\|<\infty$;

(v) for every bounded sequence $\left\{z_{n}\right\} \subset C, z \in F$, and $\left.\left\{r_{n}\right\} \quad c\right] 0, \infty\left[\right.$ with $\inf _{n \in \mathbb{N}} r_{n}>0$, if $\lim _{n \rightarrow \infty} \| z_{n+1}-$ $z_{n}\left\|=\lim _{n \rightarrow \infty}\right\| z_{n}-\Pi_{C} J^{-1}\left(J z_{n}-r_{n} A_{n} z_{n}\right) \|=$ $\lim _{n \rightarrow \infty}\left\|A_{n} z_{n}-A_{n} z\right\|=0$, then there exists a subsequence $\left\{z_{n_{i}}\right\}$ of $\left\{z_{n}\right\}$ such that $z_{n_{i}} \rightarrow z \in F$.

Let us observe some properties of the mappings and the subsets deduced from the assumptions above.

First, we know that, for any $n \in \mathbb{N}$, the image of $F$ by $A_{n}$ is a singleton. Indeed, for $z_{1}, z_{2} \in F$, we have $\left\langle z_{1}-z_{2}, A_{n} z_{1}\right\rangle \geq$ $\alpha_{n}\left\|A_{n} z_{1}-A_{n} z_{2}\right\|^{2}$ by the condition (iii). On the other hand, since $z_{1} \in \operatorname{VI}\left(C, A_{n}\right)$, it follows that $\left\langle z_{2}-z_{1}, A_{n} z_{1}\right\rangle \geq 0$. Thus, we get $A_{n} z_{1}=A_{n} z_{2}$ for all $z_{1}, z_{2} \in F$.

Next, if we assume $\bigcap_{n=1}^{\infty} A_{n}^{-1} 0 \neq \emptyset$, then we have $\bigcap_{n=1}^{\infty} A_{n}^{-1} 0=\bigcap_{n=1}^{\infty} \operatorname{VI}\left(C, A_{n}\right)$. Indeed, the inclusion $\bigcap_{n=1}^{\infty} A_{n}^{-1} 0 \quad \subset \quad \bigcap_{n=1}^{\infty} \mathrm{VI}\left(C, A_{n}\right)$ is trivial. To show the opposite inclusion, let $z \in \bigcap_{n=1}^{\infty} \mathrm{VI}\left(C, A_{n}\right)$ and $u \in \bigcap_{n=1}^{\infty} A_{n}^{-1} 0$. By the condition (iii), we have $0=\left\langle u-z, A_{n} u\right\rangle \geq \alpha_{n}\left\|A_{n} u-A_{n} z\right\|^{2}=\alpha_{n}\left\|A_{n} z\right\|^{2}$, which implies $A_{n} z=0$; that is, $z \in A_{n}^{-1} 0$ for all $n \in \mathbb{N}$. Hence, we get $\bigcap_{n=1}^{\infty} A_{n}^{-1} 0 \supset \bigcap_{n=1}^{\infty} \mathrm{VI}\left(C, A_{n}\right)$.

We also know that $F$ is closed and convex. Indeed, for $z_{1}, z_{2} \in F$ and $\left.\beta \in\right] 0,1\left[\right.$, let $z=\beta z_{1}+(1-\beta) z_{2}$. By the condition (iii), $\left\langle z-z_{1}, A_{n} z\right\rangle \geq \alpha_{n}\left\|A_{n} z-A_{n} z_{1}\right\|^{2}$ and $\left\langle z-z_{2}, A_{n} z\right\rangle \geq \alpha_{n}\left\|A_{n} z-A_{n} z_{2}\right\|^{2}$ hold for all $n \in \mathbb{N}$. Thus we get

$$
\begin{aligned}
0 & =\left\langle z-\left(\beta z_{1}+(1-\beta) z_{2}\right), A_{n} z\right\rangle \\
& =\beta\left\langle z-z_{1}, A_{n} z\right\rangle+(1-\beta)\left\langle z-z_{2}, A_{n} z\right\rangle \\
& \geq \alpha_{n}\left(\beta\left\|A_{n} z-A_{n} z_{1}\right\|^{2}+(1-\beta)\left\|A_{n} z-A_{n} z_{2}\right\|^{2}\right) \\
& \geq 0,
\end{aligned}
$$

which implies that $A_{n} z=A_{n} z_{1}=A_{n} z_{2}$ for each $n \in \mathbb{N}$. Since $\left\langle x-z_{1}, A_{n} z\right\rangle=\left\langle x-z_{1}, A_{n} z_{1}\right\rangle \geq 0$ and $\left\langle x-z_{2}, A_{n} z\right\rangle=$ $\left\langle x-z_{2}, A_{n} z_{2}\right\rangle \geq 0$ for every $n \in \mathbb{N}$ and $x \in C$, we have

$$
\left\langle x-z, A_{n} z\right\rangle=\beta\left\langle x-z_{1}, A_{n} z\right\rangle+(1-\beta)\left\langle x-z_{2}, A_{n} z\right\rangle \geq 0
$$

for all $n \in \mathbb{N}$ and $x \in C$; that is, $z \in \operatorname{VI}\left(C, A_{n}\right)$ for each $n \in \mathbb{N}$. Hence, $F$ is convex.

To see $F$ being closed, let $\left\{z_{m}\right\}$ be a sequence in $F$ such that $z_{m} \rightarrow z$. Since we have $\left\langle z-z_{m}, A_{n} z\right\rangle \geq$ $\alpha_{n}\left\|A_{n} z-A_{n} z_{m}\right\|^{2}$ for every $m, n \in \mathbb{N}$ from the condition (iii), we get $\lim _{m \rightarrow \infty}\left\|A_{n} z-A_{n} z_{m}\right\|=0$ for all $n \in \mathbb{N}$. Since $\left\langle x-z_{m}, A_{n} z_{m}\right\rangle \geq 0$ for each $m, n \in \mathbb{N}$ and $x \in C$, we obtain $\left\langle x-z, A_{n} z\right\rangle \geq 0$ for every $n \in \mathbb{N}$ and $x \in C$; that is, $z \in \operatorname{VI}\left(C, A_{n}\right)$ for all $n \in \mathbb{N}$. Therefore, $F$ is closed.

Now, we get the following result by the hybrid method using the generalized projections. 
Theorem 8. Let $C$ be a nonempty closed convex subset of a 2-uniformly convex Banach space E whose norm is uniformly Gâteaux differentiable, and let $\left\{A_{n}\right\}$ be a sequence of operators of $C$ into $E^{*}$ satisfying the conditions $(i)-(v)$. Let $\left\{\lambda_{n}\right\}$ be a sequence in ]0, $\infty$ [ such that inf ${ }_{n \in \mathbb{N}} \lambda_{n}>0$ and $\inf _{n \in \mathbb{N}}\left(2 c_{1} \alpha_{n}-\right.$ $\left.\lambda_{n}\right)>0$, where $c_{1}$ is the constant in Theorem 2. Let $x \in C$ and $\left\{x_{n}\right\}$ a sequence in $C$ generated by

$$
\begin{aligned}
x_{1} & =x, \\
y_{n} & =\Pi_{C} J^{-1}\left(J x_{n}-\lambda_{n} A_{n} x_{n}\right), \\
C_{n} & =\left\{z \in C: \phi\left(z, y_{n}\right) \leq \phi\left(z, x_{n}\right)+2 \lambda_{n}\left\langle x_{n}-z, A_{n} x_{n}\right\rangle\right\}, \\
Q_{n} & =\left\{z \in C:\left\langle x_{n}-z, J x-J x_{n}\right\rangle \geq 0\right\}, \\
x_{n+1} & =\Pi_{C_{n} \cap Q_{n}} x
\end{aligned}
$$

for each $n \in \mathbb{N}$. Then, $\left\{x_{n}\right\}$ converges strongly to $\Pi_{F} x$.

Proof. It is obvious that $Q_{n}$ is closed and convex for every $n \epsilon$ $\mathbb{N}$. Since $\phi\left(z, y_{n}\right) \leq \phi\left(z, x_{n}\right)+2 \lambda_{n}\left\langle x_{n}-z, A_{n} x_{n}\right\rangle$ if and only if $2\left\langle z, J x_{n}-J y_{n}\right\rangle+\left\|y_{n}\right\|^{2}-\left\|x_{n}\right\|^{2}-2 \lambda_{n}\left\langle x_{n}-z, A_{n} x_{n}\right\rangle \leq 0$, we have that $C_{n}$ is closed and convex for all $n \in \mathbb{N}$. Next, we show that, for $n \in \mathbb{N}, x_{n} \in C$ implies that $F \subset C_{n}$. Let $z \in F$. We have

$$
\begin{aligned}
\left(\phi\left(z, y_{n}\right)+2 \lambda_{n}\left\langle y_{n}-z, A_{n} z\right\rangle\right) \\
\quad-\left(\phi\left(z, x_{n}\right)+2 \lambda_{n}\left\langle x_{n}-z, A_{n} z\right\rangle\right) \\
=\left(\phi\left(z, y_{n}\right)-\phi\left(z, x_{n}\right)\right)+2 \lambda_{n}\left\langle y_{n}-x_{n}, A_{n} z\right\rangle \\
=-\phi\left(y_{n}, x_{n}\right)+2\left\langle y_{n}-z, J y_{n}-J x_{n}\right\rangle \\
+2 \lambda_{n}\left\langle y_{n}-x_{n}, A_{n} z\right\rangle
\end{aligned}
$$

for every $n \in \mathbb{N}$. Since $y_{n}=\Pi_{C} J^{-1}\left(J x_{n}-\lambda_{n} A_{n} x_{n}\right)$ and by Lemma 5, we get $\left\langle y_{n}-z, J x_{n}-\lambda_{n} A_{n} x_{n}-J y_{n}\right\rangle \geq 0$. Further, by Lemma 4 , we obtain

$$
\begin{aligned}
\left(\phi\left(z, y_{n}\right)\right. & \left.+2 \lambda_{n}\left\langle y_{n}-z, A_{n} z\right\rangle\right) \\
& -\left(\phi\left(z, x_{n}\right)+2 \lambda_{n}\left\langle x_{n}-z, A_{n} z\right\rangle\right) \\
\leq & -c_{1}\left\|y_{n}-x_{n}\right\|^{2}-2 \lambda_{n}\left\langle y_{n}-z, A_{n} x_{n}\right\rangle \\
& +2 \lambda_{n}\left\langle y_{n}-x_{n}, A_{n} z\right\rangle \\
= & -c_{1}\left\|y_{n}-x_{n}\right\|^{2} \\
& -2 \lambda_{n}\left(\left\langle y_{n}-x_{n}, A_{n} x_{n}\right\rangle+\left\langle x_{n}-z, A_{n} x_{n}\right\rangle\right) \\
& +2 \lambda_{n}\left\langle y_{n}-x_{n}, A_{n} z\right\rangle .
\end{aligned}
$$

Using $x_{n} \in C$ and the condition (iii), we have $\left\langle x_{n}-z, A_{n} x_{n}\right\rangle \geq$ $\alpha_{n}\left\|A_{n} x_{n}-A_{n} z\right\|^{2}$ and thus

$$
\begin{aligned}
\left(\phi\left(z, y_{n}\right)\right. & \left.+2 \lambda_{n}\left\langle y_{n}-z, A_{n} z\right\rangle\right) \\
& -\left(\phi\left(z, x_{n}\right)+2 \lambda_{n}\left\langle x_{n}-z, A_{n} z\right\rangle\right) \\
\leq & -c_{1}\left\|y_{n}-x_{n}\right\|^{2} \\
& -2 \lambda_{n}\left(\left\langle y_{n}-x_{n}, A_{n} x_{n}\right\rangle+\alpha_{n}\left\|A_{n} x_{n}-A_{n} z\right\|^{2}\right) \\
& +2 \lambda_{n}\left\langle y_{n}-x_{n}, A_{n} z\right\rangle \\
= & -c_{1}\left\|y_{n}-x_{n}\right\|^{2}-2 \lambda_{n} \alpha_{n}\left\|A_{n} x_{n}-A_{n} z\right\|^{2} \\
& -2 \lambda_{n}\left\langle y_{n}-x_{n}, A_{n} x_{n}-A_{n} z\right\rangle \\
\leq & -c_{1}\left\|y_{n}-x_{n}\right\|^{2}-2 \lambda_{n} \alpha_{n}\left\|A_{n} x_{n}-A_{n} z\right\|^{2} \\
& +2 \lambda_{n}\left\|y_{n}-x_{n}\right\|\left\|A_{n} x_{n}-A_{n} z\right\| \\
\leq & -c_{1}\left\|y_{n}-x_{n}\right\|^{2}-2 \lambda_{n} \alpha_{n}\left\|A_{n} x_{n}-A_{n} z\right\|^{2} \\
& +2 \lambda_{n}\left(\frac{\beta}{2}\left\|y_{n}-x_{n}\right\|^{2}+\frac{1}{2 \beta}\left\|A_{n} x_{n}-A_{n} z\right\|^{2}\right) \\
= & \left(\beta \lambda_{n}-c_{1}\right)\left\|y_{n}-x_{n}\right\|^{2} \\
& +\lambda_{n}\left(\frac{1}{\beta}-2 \alpha_{n}\right)\left\|A_{n} x_{n}-A_{n} z\right\|^{2}
\end{aligned}
$$

for any $\beta>0$. Since a sequence $\left\{\lambda_{n}\right\}$ satisfies $0<\lambda_{n}<2 c_{1} \alpha_{n}$ for all $n \in \mathbb{N}$, $\lim \sup _{n \rightarrow \infty} \lambda_{n}<\infty$, and $\inf _{n \in \mathbb{N}}\left(c_{1} / \lambda_{n}-\right.$ $\left.1 /\left(2 \alpha_{n}\right)\right)>0$, we can choose a positive sequence $\left\{\beta_{n}\right\}$ such that

$$
\beta_{n} \lambda_{n}-c_{1}<0, \quad \lambda_{n}\left(\frac{1}{\beta_{n}}-2 \alpha_{n}\right)<0 \quad \forall n \in \mathbb{N}
$$

$$
\limsup _{n \rightarrow \infty}\left(\beta_{n} \lambda_{n}-c_{1}\right)<0, \quad \limsup _{n \rightarrow \infty} \lambda_{n}\left(\frac{1}{\beta_{n}}-2 \alpha_{n}\right)<0 .
$$

So, we obtain

$$
\begin{aligned}
& \left(\phi\left(z, y_{n}\right)+2 \lambda_{n}\left\langle y_{n}-z, A_{n} z\right\rangle\right) \\
& \quad-\left(\phi\left(z, x_{n}\right)+2 \lambda_{n}\left\langle x_{n}-z, A_{n} z\right\rangle\right) \leq 0 .
\end{aligned}
$$

Since $z \in \operatorname{VI}\left(C, A_{n}\right)$, we have $\left\langle y_{n}-z, A_{n} z\right\rangle \geq 0$. Using $x_{n} \in C$ and the condition (ii), we have $\left\langle x_{n}-z, A_{n} z\right\rangle \leq\left\langle x_{n}-z, A_{n} x_{n}\right\rangle$. Thus, we get

$$
\phi\left(z, y_{n}\right) \leq \phi\left(z, x_{n}\right)+2 \lambda_{n}\left\langle x_{n}-z, A_{n} x_{n}\right\rangle ;
$$

that is, $F \subset C_{n}$. From this fact, we get that $F \subset C_{n} \cap Q_{n}$ for every $n \in \mathbb{N}$ and $\left\{x_{n}\right\}$ is well defined. Indeed, $x_{1}=x \in C$ is given and since $Q_{1}=C$, we have $F \subset C_{1} \cap Q_{1}$. Assume that $x_{k}$ is well defined and $F \subset C_{k} \cap Q_{k}$ for some $k \in \mathbb{N}$. There exists a unique element $x_{k+1}=\prod_{C_{k} \cap Q_{k}} x$ and we get $\left\langle x_{k+1}-z, J x-J x_{k+1}\right\rangle \geq 0$ for all $z \in C_{k} \cap Q_{k}$ by Lemma 5 . Since $F \subset C_{k} \cap Q_{k}$, we have $\left\langle x_{k+1}-z, J x-J x_{k+1}\right\rangle \geq 0$ for every 
$z \in F$; that is, $F \subset Q_{k+1}$. Since $x_{k+1} \in C_{k} \cap Q_{k} \subset C$, we have $F \subset C_{k+1}$. Hence, we obtain $F \subset C_{k+1} \cap Q_{k+1}$. By mathematical induction, we get $F \subset C_{n} \cap Q_{n}$ for every $n \in \mathbb{N}$ and $\left\{x_{n}\right\}$ is well defined. Since $x_{n+1}=\Pi_{C_{n} \cap Q_{n}} x$ and $F \subset C_{n} \cap Q_{n}$, we have $\phi\left(x_{n+1}, x\right) \leq \phi\left(\Pi_{F} x, x\right)$ for every $n \in \mathbb{N}$, which implies that $\left\{x_{n}\right\}$ is bounded. Further, since $x_{n+1} \in Q_{n}$, we have

$$
\begin{aligned}
& \phi\left(x_{n+1}, x_{n}\right)+\phi\left(x_{n}, x\right) \\
& \quad=\phi\left(x_{n+1}, x\right)+2\left\langle x_{n}-x_{n+1}, J x_{n}-J x\right\rangle \\
& \quad \leq \phi\left(x_{n+1}, x\right)
\end{aligned}
$$

for all $n \in \mathbb{N}$. Thus, there exists $\lim _{n \rightarrow \infty} \phi\left(x_{n}, x\right)$ and

$$
\lim _{n \rightarrow \infty} \phi\left(x_{n+1}, x_{n}\right)=0 .
$$

By Lemma 4, we get

$$
\lim _{n \rightarrow \infty}\left\|x_{n+1}-x_{n}\right\|=0 .
$$

Using $x_{n+1} \in C_{n}$, we have

$$
\begin{aligned}
\phi\left(x_{n+1}, y_{n}\right) & \leq \phi\left(x_{n+1}, x_{n}\right)+2 \lambda_{n}\left\langle x_{n}-x_{n+1}, A_{n} x_{n}\right\rangle \\
& \leq \phi\left(x_{n+1}, x_{n}\right)+2 \lambda_{n}\left\|x_{n}-x_{n+1}\right\|\left\|A_{n} x_{n}\right\|
\end{aligned}
$$

for all $n \in \mathbb{N}$. From the condition (iii), we have

$$
\begin{array}{r}
\left\|x_{n}-z\right\|\left\|A_{n} x_{n}\right\| \geq \alpha_{n}\left(\left\|A_{n} x_{n}\right\|-\left\|A_{n} z\right\|\right)^{2} \\
\geq \alpha_{n}\left(\left\|A_{n} x_{n}\right\|^{2}-2\left\|A_{n} x_{n}\right\|\left\|A_{n} z\right\|\right),
\end{array}
$$

which implies that

$$
\left\|x_{n}-z\right\| \geq \alpha_{n}\left\|A_{n} x_{n}\right\|-2 \alpha_{n}\left\|A_{n} z\right\|
$$

for every $n \in \mathbb{N}$ and $z \in F$. Since $0<\lim _{\inf _{n \rightarrow \infty}} \alpha_{n} \leq$ $\lim \sup _{n \rightarrow \infty} \alpha_{n}<\infty$, using the condition (iv) and the boundedness of $\left\{x_{n}\right\}$, we get that $\left\{A_{n} x_{n}\right\}$ is bounded. Since (22)-(24) hold and $\left\{\lambda_{n}\right\}$ is bounded, we have $\lim _{n \rightarrow \infty} \phi\left(x_{n+1}, y_{n}\right)=0$, which implies that

$$
\lim _{n \rightarrow \infty}\left\|x_{n+1}-y_{n}\right\|=0
$$

by Lemma 4. From (23) and (27), we also have $\lim _{n \rightarrow \infty} \| x_{n}-$ $y_{n} \|=0$. Using the facts that

$$
\begin{aligned}
\left(\phi\left(z, y_{n}\right)\right. & \left.+2 \lambda_{n}\left\langle y_{n}-z, A_{n} z\right\rangle\right) \\
& -\left(\phi\left(z, x_{n}\right)+2 \lambda_{n}\left\langle x_{n}-z, A_{n} z\right\rangle\right) \\
= & 2\left\langle z, J x_{n}-J y_{n}\right\rangle+\left(\left\|y_{n}\right\|^{2}-\left\|x_{n}\right\|^{2}\right) \\
& +2 \lambda_{n}\left\langle y_{n}-x_{n}, A_{n} z\right\rangle
\end{aligned}
$$

for all $n \in \mathbb{N}, \lim _{n \rightarrow \infty}\left\|x_{n}-y_{n}\right\|=0$, the condition (iv) holds, $\left\{x_{n}\right\},\left\{y_{n}\right\}$, and $\left\{\lambda_{n}\right\}$ are bounded, and the duality mapping $J$ is norm-to-weak ${ }^{*}$ uniformly continuous on bounded subset of $E$, we obtain

$$
\begin{aligned}
\lim _{n \rightarrow \infty}( & \left(\phi\left(z, y_{n}\right)+2 \lambda_{n}\left\langle y_{n}-z, A_{n} z\right\rangle\right) \\
& \left.-\left(\phi\left(z, x_{n}\right)+2 \lambda_{n}\left\langle x_{n}-z, A_{n} z\right\rangle\right)\right)=0 .
\end{aligned}
$$

Since (17) holds for every $n \in \mathbb{N}$, it follows from (29) and $\lim _{n \rightarrow \infty}\left\|x_{n}-y_{n}\right\|=0$ that

$$
\lim _{n \rightarrow \infty}\left\|A_{n} x_{n}-A_{n} z\right\|=0 .
$$

From the condition (v), there exists a subsequence $\left\{x_{n_{i}}\right\}$ of $\left\{x_{n}\right\}$ such that $x_{n_{i}} \rightarrow z \in F$. Since the norm of $E$ is weakly lower semicontinuous, we get

$$
\begin{aligned}
\phi(z, x) & =\|z\|^{2}-2\langle z, J x\rangle+\|x\|^{2} \\
& \leq \liminf _{i \rightarrow \infty}\left(\left\|x_{n_{i}}\right\|^{2}-2\left\langle x_{n_{i}}, J x\right\rangle+\|x\|^{2}\right) \\
& =\liminf _{i \rightarrow \infty} \phi\left(x_{n_{i}}, x\right)=\lim _{n \rightarrow \infty} \phi\left(x_{n}, x\right) \leq \phi\left(\Pi_{F} x, x\right),
\end{aligned}
$$

which implies $z=\Pi_{F} x$ and

$$
\lim _{n \rightarrow \infty} \phi\left(x_{n}, x\right)=\phi\left(\Pi_{F} x, x\right) .
$$

Using $x_{n+1}=\Pi_{C_{n} \cap Q_{n}} x, F \subset C_{n} \cap Q_{n}$, and Lemma 5, we have

$$
\begin{aligned}
0 & \geq\left\langle x_{n+1}-\Pi_{F} x, J x_{n+1}-J x\right\rangle \\
& =\frac{1}{2}\left(\phi\left(\Pi_{F} x, x_{n+1}\right)+\phi\left(x_{n+1}, x\right)-\phi\left(\Pi_{F} x, x\right)\right)
\end{aligned}
$$

which implies that

$$
\phi\left(\Pi_{F} x, x\right) \geq \phi\left(\Pi_{F} x, x_{n+1}\right)+\phi\left(x_{n+1}, x\right)
$$

for all $n \in \mathbb{N}$. From (32), we get $\lim _{n \rightarrow \infty} \phi\left(\Pi_{F} x, x_{n+1}\right)=0$ and by Lemma 4 , we obtain $x_{n} \rightarrow \Pi_{F} x$, which is the desired result.

Next, we have the following result by the hybrid method using the metric projections.

Theorem 9. Assume that $E, C,\left\{A_{n}\right\},\left\{\lambda_{n}\right\}$, and $c_{1}$ are the same as in Theorem 8. Let $x \in C$ and $\left\{x_{n}\right\}$ a sequence in $C$ generated by

$$
\begin{aligned}
x_{1} & =x, \\
y_{n} & =\Pi_{C} J^{-1}\left(J x_{n}-\lambda_{n} A_{n} x_{n}\right), \\
C_{n} & =\left\{z \in C: \phi\left(z, y_{n}\right) \leq \phi\left(z, x_{n}\right)+2 \lambda_{n}\left\langle x_{n}-z, A_{n} x_{n}\right\rangle\right\}, \\
Q_{n} & =\left\{z \in C:\left\langle x_{n}-z, J\left(x-x_{n}\right)\right\rangle \geq 0\right\}, \\
x_{n+1} & =P_{C_{n} \cap Q_{n}} x
\end{aligned}
$$

for each $n \in \mathbb{N}$. Then, $\left\{x_{n}\right\}$ converges strongly to $P_{F} x$.

Proof. $Q_{n}$ is closed convex for every $n \in \mathbb{N}$. As in the proof of Theorem 8, we have that $C_{n}$ is closed and convex. We also get that, for $n \in \mathbb{N}, x_{n} \in C$ implies that $F \subset C_{n}$. By this fact, we obtain $F \subset C_{n} \cap Q_{n}$ for every $n \in \mathbb{N}$ and $\left\{x_{n}\right\}$ is well defined. Indeed, $x_{1}=x \in C$ is given and $F \subset C_{1} \cap Q_{1}$ since $Q_{1}=C$. Assume that $x_{k}$ is well defined and $F \subset C_{k} \cap Q_{k}$ for some 
$k \in \mathbb{N}$. There exists a unique element $x_{k+1}=P_{C_{k} \cap Q_{k}} x$ and we get $\left\langle x_{k+1}-z, J\left(x-x_{k+1}\right)\right\rangle \geq 0$ for all $z \in C_{k} \cap Q_{k}$ by Lemma 6 . Since $F \subset C_{k} \cap Q_{k}$, we have $\left\langle x_{k+1}-z, J\left(x-x_{k+1}\right)\right\rangle \geq 0$ for every $z \in F$; that is, $F \subset Q_{k+1}$. Since $x_{k+1} \in C_{k} \cap Q_{k} \subset C$, we also have $F \subset C_{k+1}$. Thus, we obtain $F \subset C_{k+1} \cap Q_{k+1}$. By mathematical induction, we get $F \subset C_{n} \cap Q_{n}$ for every $n \in \mathbb{N}$ and $\left\{x_{n}\right\}$ is well defined.

Since $x_{n+1}=P_{C_{n} \cap Q_{n}} x$ and $F \subset C_{n} \cap Q_{n}$, we have

$$
\left\|x_{n+1}-x\right\| \leq\left\|x-P_{F} x\right\|
$$

for every $n \in \mathbb{N}$ and, hence, $\left\{x_{n}\right\}$ is bounded. Using $x_{n+1} \in Q_{n}$ and Theorem 2, we have

$$
\begin{aligned}
\| x_{n+1} & -x\left\|^{2}-\right\| x_{n}-x \|^{2} \\
& \geq 2\left\langle x_{n+1}-x_{n}, J\left(x_{n}-x\right)\right\rangle+c_{1}\left\|x_{n+1}-x_{n}\right\|^{2} \\
& \geq c_{1}\left\|x_{n+1}-x_{n}\right\|^{2}
\end{aligned}
$$

for each $n \in \mathbb{N}$, which implies that there exists $\lim _{n \rightarrow \infty} \| x_{n}-$ $x \|$ and

$$
\lim _{n \rightarrow \infty}\left\|x_{n+1}-x_{n}\right\|=0 .
$$

Since $y_{n}=\Pi_{C} J^{-1}\left(J x_{n}-\lambda_{n} A_{n} x_{n}\right)$, by Lemma 5 , we have

$$
\left\langle y_{n}-x_{n}, J x_{n}-J y_{n}-\lambda_{n} A_{n} x_{n}\right\rangle \geq 0,
$$

which implies that

$$
\begin{aligned}
-c_{1}\left\|x_{n}-y_{n}\right\|^{2} & \geq \frac{1}{2}\left(-\phi\left(y_{n}, x_{n}\right)-\phi\left(x_{n}, y_{n}\right)\right) \\
& =\left\langle y_{n}-x_{n}, J x_{n}-J y_{n}\right\rangle \\
& \geq \lambda_{n}\left\langle y_{n}-x_{n}, A_{n} x_{n}\right\rangle \\
& \geq-\lambda_{n}\left\|y_{n}-x_{n}\right\|\left\|A_{n} x_{n}\right\|
\end{aligned}
$$

from Lemma 4. As in the proof of Theorem $8,\left\{A_{n} x_{n}\right\}$ is bounded. Thus, we get that $\left\{\left\|y_{n}-x_{n}\right\|\right\}$ is also bounded by the boundedness of $\left\{\lambda_{n}\right\}$ and so is $\left\{y_{n}\right\}$. Since $x_{n+1} \in C_{n}$, we have $\phi\left(x_{n+1}, y_{n}\right) \leq \phi\left(x_{n+1}, x_{n}\right)+2 \lambda_{n}\left\langle x_{n}-x_{n+1}, A_{n} x_{n}\right\rangle$; that is,

$$
\begin{aligned}
& \phi\left(x_{n}, y_{n}\right) \\
& \quad \leq 2\left\langle x_{n}-x_{n+1}, J x_{n}-J y_{n}\right\rangle+2 \lambda_{n}\left\langle x_{n}-x_{n+1}, A_{n} x_{n}\right\rangle
\end{aligned}
$$

for all $n \in \mathbb{N}$. By the boundedness of $\left\{x_{n}\right\},\left\{y_{n}\right\},\left\{\lambda_{n}\right\}$, and $\left\{A_{n} x_{n}\right\}$ with (38) and Lemma 4 , we have

$$
\lim _{n \rightarrow \infty}\left\|x_{n}-y_{n}\right\|=0 .
$$

As in the proof of Theorem 8, using (17) and (29), we have

$$
\lim _{n \rightarrow \infty}\left\|A_{n} x_{n}-A_{n} z\right\|=0 .
$$

From the condition (v), there exists a subsequence $\left\{x_{n_{i}}\right\}$ of $\left\{x_{n}\right\}$ such that $x_{n_{i}} \rightarrow z \in F$. Since the norm of $E$ is weakly lower semicontinuous and (36) holds, we get

$$
\begin{aligned}
\|z-x\| & \leq \liminf _{i \rightarrow \infty}\left\|x_{n_{i}}-x\right\| \\
& =\lim _{n \rightarrow \infty}\left\|x_{n}-x\right\| \leq\left\|P_{F} x-x\right\|
\end{aligned}
$$

which implies that $z=P_{F} x$ and

$$
\lim _{n \rightarrow \infty}\left\|x_{n}-x\right\|=\left\|P_{F} x-x\right\|
$$

Using the facts that $x_{n+1}=P_{C_{n} \cap Q_{n}} x$ and $F \subset C_{n} \cap Q_{n}$ and by Theorem 2, we obtain

$$
\begin{aligned}
\| x- & P_{F} x \|^{2} \\
\geq & \left\|x-x_{n+1}\right\|^{2}+2\left\langle x_{n+1}-P_{F} x, J\left(x-x_{n+1}\right)\right\rangle \\
& +c_{1}\left\|x_{n+1}-P_{F} x\right\|^{2} \\
\geq & \left\|x-x_{n+1}\right\|^{2}+c_{1}\left\|x_{n+1}-P_{F} x\right\|^{2}
\end{aligned}
$$

for all $n \in \mathbb{N}$. By (45), we have

$$
\lim _{n \rightarrow \infty}\left\|x_{n+1}-P_{F} x\right\|=0,
$$

which is the desired result.

Remark 10. Even though we replace the definition of $C_{n}$ in Theorems 8 and 9 with

$$
C_{n}=\left\{\begin{array}{c}
\left\{z \in C: \phi\left(z, y_{n}\right) \leq \phi\left(z, x_{n}\right)\right\} \\
\left(A_{n} z=0 \forall z \in F\right), \\
\left\{z \in C: \phi\left(z, y_{n}\right) \leq \phi\left(z, x_{n}\right)\right. \\
\left.+2 \lambda_{n}\left\langle x_{n}-z, A_{n} x_{n}\right\rangle\right\} \\
\left(A_{n} z \neq 0 \text { for some } z \in F\right),
\end{array}\right.
$$

the theorems are still valid.

\section{The Variational Inequality Problem for Monotone Operators}

Let $I$ be a countable set and $i: \mathbb{N} \rightarrow I$ a mapping. Nakajo et al. [30] propose the condition (NST) as follows: $i$ satisfies the condition (NST) if there exists a subsequence $\left\{n_{k}\right\}$ of $\mathbb{N}$ such that, for any $j \in I$, there is $M_{j} \in \mathbb{N}$ with $j \in$ $\left\{i\left(n_{k}\right), i\left(n_{k}+1\right), \ldots, i\left(n_{k}+M_{j}-1\right)\right\}$ for all sufficiently large $k \in \mathbb{N}$. Using the condition (NST), we get the following result for the variational inequality problem by Theorem 8 .

Theorem 11. Let $C$ be a nonempty closed convex subset of a 2-uniformly convex and uniformly smooth Banach space E, I a countable set, and $\left\{B_{i}\right\}_{i \in I}$ a family of operators of $C$ into $E^{*}$ such that

(i) $F=\bigcap_{i \in I} V I\left(C, B_{i}\right) \neq \emptyset$;

(ii) $B_{i}$ is an inverse strongly monotone operator for each $i \epsilon$ $I$; that is, there exists $\left.\left\{\beta_{i}: i \in I\right\} \subset\right] 0, \infty[$ such that for every $i \in I$ and $x, y \in C$, the inequality $\left\langle x-y, B_{i} x-\right.$ $\left.B_{i} y\right\rangle \geq \beta_{i}\left\|B_{i} x-B_{i} y\right\|^{2}$ holds;

(iii) for all $z \in F, \sup _{i \in I}\left\|B_{i} z\right\|<\infty$.

Suppose that the index mapping $i: \mathbb{N} \rightarrow I$ satisfies the condition (NST) and $0<\lim _{\inf _{n \rightarrow \infty}} \beta_{i(n)} \leq \limsup _{n \rightarrow \infty} \beta_{i(n)}<$ $\infty$. Let $\left\{\lambda_{n}\right\}$ be a sequence in $] 0, \infty\left[\right.$ such that inf $f_{n \in \mathbb{N}} \lambda_{n}>0$ and 
$\inf _{n \in \mathbb{N}}\left(2 c_{1} \beta_{i(n)}-\lambda_{n}\right)>0$, where $c_{1}$ is the constant in Theorem 2. Let $x \in C$ and $\left\{x_{n}\right\}$ a sequence in $C$ generated by

$$
\begin{aligned}
& x_{1}=x \text {, } \\
& y_{n}=\Pi_{C} J^{-1}\left(J x_{n}-\lambda_{n} B_{i(n)} x_{n}\right), \\
& C_{n}=\left\{z \in C: \phi\left(z, y_{n}\right) \leq \phi\left(z, x_{n}\right)\right. \\
& \left.+2 \lambda_{n}\left\langle x_{n}-z, B_{i(n)} x_{n}\right\rangle\right\}, \\
& Q_{n}=\left\{z \in C:\left\langle x_{n}-z, J x-J x_{n}\right\rangle \geq 0\right\}, \\
& x_{n+1}=\Pi_{C_{n} \cap Q_{n}} x
\end{aligned}
$$

for each $n \in \mathbb{N}$. Then, $\left\{x_{n}\right\}$ converges strongly to $\Pi_{F} x$.

Proof. We apply Theorem 8 with $A_{n}=B_{i(n)}$ for all $n \in \mathbb{N}$. Then, the conditions (i)-(iv) are satisfied, and we will verify the condition (v). Let $\left\{z_{n}\right\}$ be a bounded sequence in $C$ with

$$
\begin{aligned}
\lim _{n \rightarrow \infty}\left\|z_{n+1}-z_{n}\right\| & =\lim _{n \rightarrow \infty}\left\|z_{n}-\Pi_{C} J^{-1}\left(J z_{n}-r_{n} A_{n} z_{n}\right)\right\| \\
& =0,
\end{aligned}
$$

$\left.\left\{r_{n}\right\} \subset\right] 0, \infty\left[\right.$ with $\lim \inf _{n \rightarrow \infty} r_{n}>0$, and $z \in F$ such that $\lim _{n \rightarrow \infty}\left\|A_{n} z_{n}-A_{n} z\right\|=0$. By the condition (NST), there exists a weakly convergent subsequence $\left\{z_{n_{k}}\right\}$ of $\left\{z_{n}\right\}$ such that, for any $i \in I$, there is $M_{i} \in \mathbb{N}$ with $i \in\left\{i\left(n_{k}\right), i\left(n_{k}+\right.\right.$ $\left.1), \ldots, i\left(n_{k}+M_{i}-1\right)\right\}$ for all sufficiently large $k \in \mathbb{N}$. Let $z_{n_{k}} \rightarrow u$ and fix $i \in I$. There exists $j_{k} \in\left\{0,1, \ldots, M_{i}-1\right\}$ such that $i\left(n_{k}+j_{k}\right)=i$ for every sufficiently large $k \in \mathbb{N}$. We consider a subsequence of $\left\{n_{k}+j_{k}\right\}$ for all $k \in\{k \in \mathbb{N}$ : $\left.n_{k}+j_{k}<n_{k+1}+j_{k+1}\right\}$ and denote it by $\left\{n_{k}+j_{k}\right\}$ again. We have

$$
\left\|z_{n_{k}+j_{k}}-z_{n_{k}}\right\| \leq \sum_{l=n_{k}}^{n_{k}+M_{i}-1}\left\|z_{l+1}-z_{l}\right\|
$$

for all $k \in \mathbb{N}$, which implies that $z_{n_{k}+j_{k}} \rightarrow u$. Let $y_{n}=$ $\Pi_{C} J^{-1}\left(J z_{n}-r_{n} A_{n} z_{n}\right)$. By Lemma 5, we have

$$
\begin{aligned}
& \left\|y_{n_{k}+j_{k}}-y\right\|\left\|J z_{n_{k}+j_{k}}-J y_{n_{k}+j_{k}}\right\| \\
& \geq\left\langle y_{n_{k}+j_{k}}-y, J z_{n_{k}+j_{k}}-J y_{n_{k}+j_{k}}\right\rangle \\
& \geq r_{n_{k}+j_{k}}\left\langle y_{n_{k}+j_{k}}-y, A_{n_{k}+j_{k}} z_{n_{k}+j_{k}}\right\rangle
\end{aligned}
$$

for every sufficiently large $k \in \mathbb{N}$ and $y \in C$. Since $A_{n_{k}+j_{k}}=$ $B_{i\left(n_{k}+j_{k}\right)}=B_{i}$ for each sufficiently large $k \in \mathbb{N}, y_{n_{k}+j_{k}} \rightarrow u$, $\left\|z_{n_{k}+j_{k}}-y_{n_{k}+j_{k}}\right\| \rightarrow 0, \lim _{\inf _{n \rightarrow \infty}} r_{n}>0, \lim _{k \rightarrow \infty} \| B_{i} z_{n_{k}+j_{k}}-$ $B_{i} z \| \stackrel{=}{=}$, and the duality mapping $J$ is uniformly continuous on bounded subset of $E$, we have

$$
\left\langle y-u, B_{i} z\right\rangle \geq 0
$$

for all $y \in C$. Since $B_{i}$ is inverse strongly monotone, we have

$$
\left\langle z_{n_{k}+j_{k}}-u, B_{i} z_{n_{k}+j_{k}}-B_{i} u\right\rangle \geq \beta_{i}\left\|B_{i} z_{n_{k}+j_{k}}-B_{i} u\right\|^{2}
$$

for every $k \in \mathbb{N}$, which implies that

$$
0=\left\langle u-u, B_{i} z-B_{i} u\right\rangle \geq \beta_{i}\left\|B_{i} z-B_{i} u\right\|^{2} ;
$$

that is, $B_{i} z=B_{i} u$. From (53),

$$
\left\langle y-u, B_{i} u\right\rangle \geq 0
$$

for all $y \in C$. Therefore, $u \in \operatorname{VI}\left(C, B_{i}\right)$ for every $i \in I$; that is, $u \in F$. Hence, the condition (v) is satisfied. Consequently, we obtain $x_{n} \rightarrow \Pi_{F} x$ by Theorem 8 .

As in the proof of Theorem 11, we get the following result for the variational inequality problem by Theorem 9 .

Theorem 12. Assume that E, $C, I,\left\{B_{i}\right\}, F, c_{1}, i,\left\{\beta_{i}\right\}$, and $\left\{\lambda_{n}\right\}$ are the same as Theorem 11. Let $x \in C$ and $\left\{x_{n}\right\}$ a sequence in $C$ generated by

$$
\begin{aligned}
& x_{1}=x, \\
& \begin{aligned}
& y_{n}= \Pi_{C} J^{-1}\left(J x_{n}-\lambda_{n} B_{i(n)} x_{n}\right), \\
& C_{n}=\left\{z \in C: \phi\left(z, y_{n}\right) \leq \phi\left(z, x_{n}\right)\right. \\
&\left.\quad+2 \lambda_{n}\left\langle x_{n}-z, B_{i(n)} x_{n}\right\rangle\right\}, \\
& Q_{n}=\{z \in C:\left.\left\langle x_{n}-z, J\left(x-x_{n}\right)\right\rangle \geq 0\right\}, \\
& x_{n+1}= P_{C_{n} \cap Q_{n}} x
\end{aligned}
\end{aligned}
$$

for each $n \in \mathbb{N}$. Then, $\left\{x_{n}\right\}$ converges strongly to $P_{F} x$.

Remark 13. In Theorems 11 and 12, under the assumption that $\bigcap_{i \in I} B_{i}^{-1} 0 \neq \emptyset$, we have $\operatorname{VI}\left(C, B_{i}\right)=B_{i}^{-1} 0$ for all $i \in I$. Indeed, $B_{i}^{-1} 0 \subset \mathrm{VI}\left(C, B_{i}\right)$ is trivial. Let $i \in I, u \in \operatorname{VI}\left(C, B_{i}\right)$, and $z \in$ $B_{i}^{-1} 0$. From the condition (ii), we have $\left\langle z-u, B_{i} z-B_{i} u\right\rangle \geq$ $\beta_{i}\left\|B_{i} z-B_{i} u\right\|^{2}$ which implies that $-\left\langle z-u, B_{i} u\right\rangle \geq \beta_{i}\left\|B_{i} u\right\|^{2}$. On the other hand, $\left\langle z-u, B_{i} u\right\rangle \geq 0$ from $u \in \operatorname{VI}\left(C, B_{i}\right)$. So, we obtain $u \in B_{i}^{-1} 0$; that is, $\operatorname{VI}\left(C, B_{i}\right) \subset B_{i}^{-1} 0$. Therefore, $B_{i}^{-1} 0=$ $\operatorname{VI}\left(C, B_{i}\right)$ for all $i \in I$. Now suppose that $F=\bigcap_{i \in I} B_{i}^{-1} 0 \neq \emptyset$ instead of the condition (i) and $C_{n}=\left\{z \in C: \phi\left(z, y_{n}\right) \leq\right.$ $\left.\phi\left(z, x_{n}\right)\right\}$. By the argument mentioned above and Remark 10, Theorems 11 and 12 hold under the conditions (i) and (ii) and we get the result of [19].

Remark 14. We know that, for a continuously Fréchet differentiable and convex functional $f$ on a Banach space $E$, if $\nabla f$ is Lipschitz continuous with constant $1 / \alpha$, then $\nabla f$ is $\alpha$ inverse strongly monotone operator; see $[2,19]$. So, we can apply Theorems 11 and 12 and Remark 13 to such a functional; see [19].

\section{The Proximal Point Algorithm}

Let $E$ be a strictly convex, reflexive, and smooth Banach space, $T \subset E \times E^{*}$ a maximal monotone operator with $T^{-1} 0 \neq \emptyset$, $r>0$, and $A x=J\left(x-J_{r} x\right)$ for all $x \in E$, where $J_{r}$ is the resolvent of $T$. Then, $A$ is well defined as a mapping of $E$ into $E^{*}$ for all $r>0$. We also have

$$
\begin{gathered}
\operatorname{VI}(E, A)=T^{-1} 0, \\
\langle x-u, A x\rangle \geq\|A x\|^{2} \quad \forall x \in E, u \in T^{-1} 0 .
\end{gathered}
$$


In fact, $\operatorname{VI}(E, A)=T^{-1} 0$ since $u \in T^{-1} 0$ is equivalent to $J_{r} u=$ $u$ and $A u=0$. Let $x \in E$ and $u \in T^{-1} 0$. Since $(1 / r) J(x-$ $\left.J_{r} x\right) \in T J_{r} x$ and $0 \in T u$, we have $\left\langle J_{r} x-u, J\left(x-J_{r} x\right)\right\rangle \geq$ 0 which implies that $\langle x-u, A x\rangle \geq\|A x\|^{2}$. By Theorem 8 and Remark 10, we get the following result using the index mapping which satisfies the condition (NST).

Theorem 15. Let I be a countable set, E a 2-uniformly convex Banach space whose norm is uniformly Gâteaux differentiable, and $\left\{T_{i}\right\}_{i \in I}$ a family of maximal monotone operators of $E$ into $E^{*}$ such that $F=\bigcap_{i \in I} T_{i}^{-1} 0 \neq \emptyset$. Let $\left\{r_{n}\right\}$ be a sequence in $] 0, \infty[$ with $\lim \inf _{n \rightarrow \infty} r_{n}>0$ and $\left\{\lambda_{n}\right\}_{n \in \mathbb{N}}$ a sequence in $] 0, \infty[$ such that $\inf _{n \in \mathbb{N}} \lambda_{n}>0$ and $\inf _{n \in \mathbb{N}}\left(2 c_{1}-\lambda_{n}\right)>0$, where $c_{1}$ is the constant in Theorem 2. Let $x \in E$ and $\left\{x_{n}\right\}_{n \in \mathbb{N}}$ a sequence in $E$ generated by

$$
\begin{aligned}
x_{1} & =x, \\
y_{n} & =J^{-1}\left(J x_{n}-\lambda_{n} J\left(x_{n}-J_{r_{n}}^{T_{i(n)}} x_{n}\right)\right), \\
C_{n} & =\left\{z \in E: \phi\left(z, y_{n}\right) \leq \phi\left(z, x_{n}\right)\right\}, \\
Q_{n} & =\left\{z \in E:\left\langle x_{n}-z, J x-J x_{n}\right\rangle \geq 0\right\}, \\
x_{n+1} & =\Pi_{C_{n} \cap Q_{n}} x
\end{aligned}
$$

for each $n \in \mathbb{N}$, where the index mapping $i: \mathbb{N} \rightarrow$ I satisfies the condition (NST) and $J_{r_{n}}^{T_{i(n)}}$ is the resolvent of $T_{i(n)}$. Then, $\left\{x_{n}\right\}$ converges strongly to $\Pi_{F} x$.

Proof. Suppose that $A_{n} x=J\left(x-J_{r_{n}}^{T_{i(n)}} x\right)$ for every $n \in \mathbb{N}$ and $x \in E$ in Theorem 8. Then, we have that $A_{n}$ is a mapping of $E$ into $E^{*}$ with $\bigcap_{n \in \mathbb{N}} \operatorname{VI}\left(E, A_{n}\right)=F \neq \emptyset$, the condition (iii) is satisfied with $\alpha_{n}=1$ for all $n \in \mathbb{N}$, and the conditions (ii) and (iv) hold by $A_{n} z=0$ for all $n \in \mathbb{N}$ and all $z \in F$. Let $\left\{z_{n}\right\}$ be a bounded sequence in $E, z \in F$, and $\left\{r_{n}\right\} \subset$ ] $0, \infty$ [ with $\lim \inf _{n \rightarrow \infty} r_{n}>0$. Assume that

$$
\begin{aligned}
\lim _{n \rightarrow \infty}\left\|z_{n+1}-z_{n}\right\| & =\lim _{n \rightarrow \infty}\left\|z_{n}-J^{-1}\left(J z_{n}-r_{n} A_{n} z_{n}\right)\right\| \\
& =\lim _{n \rightarrow \infty}\left\|A_{n} z_{n}-A_{n} z\right\|=0 .
\end{aligned}
$$

By the condition (NST), there exists a subsequence $\left\{z_{n_{k}}\right\}$ of $\left\{z_{n}\right\}$ such that, for any $i \in I$, there is $M_{i} \in \mathbb{N}$ with $i \in$ $\left\{i\left(n_{k}\right), i\left(n_{k}+1\right), \ldots, i\left(n_{k}+M_{i}-1\right)\right\}$ for all sufficiently large $k \in \mathbb{N}$. Let $z_{n_{k}} \rightarrow u$ and $i \in I$. As in the proof of Theorem 11, there exists $j_{k} \in\left\{0,1, \ldots, M_{i}-1\right\}$ such that $i\left(n_{k}+j_{k}\right)=i$ for every sufficiently large $k \in \mathbb{N}$ and we get $z_{n_{k}+j_{k}} \rightarrow u$. Let $\left(v, v^{*}\right) \in T_{i}$. Since

$$
\begin{gathered}
\left\langle J_{r_{n_{k}+j_{k}}}^{T_{i}} z_{n_{k}+j_{k}}-v, \frac{1}{r_{n_{k}+j_{k}}} J\left(z_{n_{k}+j_{k}}-J_{r_{n_{k}+j_{k}}}^{T_{i}} z_{n_{k}+j_{k}}\right)-v^{*}\right\rangle \geq 0, \\
\lim _{k \rightarrow \infty}\left\|z_{n_{k}+j_{k}}-J_{r_{n_{k}+j_{k}}}^{T_{i}} z_{n_{k}+j_{k}}\right\|=0,
\end{gathered}
$$

we obtain

$$
\left\langle u-v,-v^{*}\right\rangle \geq 0
$$

for each $\left(v, v^{*}\right) \in T_{i}$. As $T_{i}$ is a maximal monotone operator, $u \in T_{i}^{-1} 0$ for every $i \in I$. So, we get $u \in F$. Therefore, the condition (v) holds. So, we get conclusion by Theorem 8 and Remark 10.

As in the proof of Theorem 15, we get the following result from Theorem 9 and Remark 10.

Theorem 16. Assume that $E, I,\left\{T_{i}\right\}, F,\left\{r_{n}\right\},\left\{\lambda_{n}\right\}, c_{1}, i$, and $J_{r_{n}}^{T_{i(n)}}$ are the same as Theorem 15. Let $x \in E$ and let $\left\{x_{n}\right\}$ be a sequence in E generated by

$$
\begin{aligned}
x_{1} & =x, \\
y_{n} & =J^{-1}\left(J x_{n}-\lambda_{n} J\left(x_{n}-J_{r_{n}}^{T_{i(n)}} x_{n}\right)\right), \\
C_{n} & =\left\{z \in E: \phi\left(z, y_{n}\right) \leq \phi\left(z, x_{n}\right)\right\}, \\
Q_{n} & =\left\{z \in E:\left\langle x_{n}-z, J\left(x-x_{n}\right)\right\rangle \geq 0\right\}, \\
x_{n+1} & =P_{C_{n} \cap Q_{n}} x
\end{aligned}
$$

for each $n \in \mathbb{N}$. Then, $\left\{x_{n}\right\}$ converges strongly to $P_{F} x$.

Let $f: E \rightarrow]-\infty, \infty$ ] be a proper, lower semicontinuous, and convex function. Then, it is known that the subdifferential $\partial f$ of $f$ defined by

$$
\begin{aligned}
\partial f(x)=\left\{x^{*} \in E^{*}\right. & : f(y) \\
& \left.\geq f(x)+\left\langle y-x, x^{*}\right\rangle \forall y \in E\right\}
\end{aligned}
$$

for all $x \in E$ is a maximal monotone operator [31, 32]. Moreover, when $E$ is strictly convex, reflexive, and smooth, we know that, for the resolvent of $\partial f$,

$$
J_{r}^{\partial f} x=\underset{y \in E}{\operatorname{argmin}}\left(f(y)+\frac{1}{2 r}\|y-x\|^{2}\right)
$$

for every $r>0$ and $x \in E$ and $\partial f^{-1} 0=\operatorname{argmin}_{y \in E} f(y)$; see [21] for more details. Now, we have the following results from Theorems 15 and 16.

Theorem 17. Let I be a countable set, E a 2-uniformly convex Banach space whose norm is uniformly Gâteaux differentiable, and $\left\{f_{i}\right\}_{i \in I}$ a family of proper, lower semicontinuous, and convex functions of $E$ into ] $-\infty, \infty]$ such that $F=$ $\bigcap_{i \in I} \operatorname{argmin}_{y \in E} f_{i}(y) \neq \emptyset$. Let $\left\{r_{n}\right\}$ be a sequence in $] 0, \infty[$ with $\lim \inf _{n \rightarrow \infty} r_{n}>0$ and $\left\{\lambda_{n}\right\}_{n \in \mathbb{N}}$ a sequence in $] 0, \infty[$ such that inf $\operatorname{in\in \mathbb {N}}_{n} \lambda_{n}>0$ and $\inf _{n \in \mathbb{N}}\left(2 c_{1}-\lambda_{n}\right)>0$, where $c_{1}$ is the constant in Theorem 2. Let $x \in E$ and let $\left\{x_{n}\right\}_{n \in \mathbb{N}}$ be a sequence in E generated by

$$
\begin{aligned}
& x_{1}=x, \\
& u_{n}=\underset{y \in E}{\operatorname{argmin}}\left(f_{i(n)}(y)+\frac{1}{2 r_{n}}\left\|y-x_{n}\right\|^{2}\right), \\
& y_{n}=J^{-1}\left(J x_{n}-\lambda_{n} J\left(x_{n}-u_{n}\right)\right),
\end{aligned}
$$




$$
\begin{aligned}
C_{n} & =\left\{z \in E: \phi\left(z, y_{n}\right) \leq \phi\left(z, x_{n}\right)\right\}, \\
Q_{n} & =\left\{z \in E:\left\langle x_{n}-z, J x-J x_{n}\right\rangle \geq 0\right\}, \\
x_{n+1} & =\prod_{C_{n} \cap Q_{n}} x
\end{aligned}
$$

for each $n \in \mathbb{N}$, where the index mapping $i: \mathbb{N} \rightarrow$ I satisfies the condition (NST). Then, $\left\{x_{n}\right\}$ converges strongly to $\Pi_{F} x$.

Theorem 18. Assume that $E, I,\left\{f_{i}\right\}, F,\left\{r_{n}\right\},\left\{\lambda_{n}\right\}, c_{1}$, and $i$ are the same as Theorem 17. Let $x \in E$ and let $\left\{x_{n}\right\}$ be a sequence in E generated by

$$
\begin{aligned}
x_{1} & =x, \\
u_{n} & =\underset{y \in E}{\operatorname{argmin}}\left(f_{i(n)}(y)+\frac{1}{2 r_{n}}\left\|y-x_{n}\right\|^{2}\right) \\
y_{n} & =J^{-1}\left(J x_{n}-\lambda_{n} J\left(x_{n}-u_{n}\right)\right), \\
C_{n} & =\left\{z \in E: \phi\left(z, y_{n}\right) \leq \phi\left(z, x_{n}\right)\right\}, \\
Q_{n} & =\left\{z \in E:\left\langle x_{n}-z, J\left(x-x_{n}\right)\right\rangle \geq 0\right\}, \\
x_{n+1} & =P_{C_{n} \cap Q_{n}} x
\end{aligned}
$$

for each $n \in \mathbb{N}$. Then, $\left\{x_{n}\right\}$ converges strongly to $P_{F} x$.

At the end of this section, we make a remark about a result of the problem of image recovery due to [33, 34]. Let $i_{C}$ be the indicator function of a nonempty closed convex subset $C$ of $E$. We know that $\left.i_{C}: E \rightarrow\right]-\infty, \infty$ [ is proper lower semicontinuous and convex and, for a nonempty closed convex subset $C$ of a strictly convex, reflexive, and smooth Banach space $E,\left(\partial i_{C}\right)^{-1} 0=C$ and $J_{r}^{\partial i_{C}} x=P_{C}(x)$ for every $r>0$ and $x \in E$; see [15]. So, when $f_{j}=i_{C_{j}}$ for nonempty closed convex subset $C_{j}$ of $E$ for every $j \in I$ with $\bigcap_{j \in I} C_{j} \neq \emptyset$ in Theorems 17 and 18, we get the strong convergence to a common point of $\left\{C_{j}\right\}_{j \in I}$.

\section{Conflict of Interests}

The authors declare that there is no conflict of interests regarding the publication of this paper.

\section{Acknowledgment}

The first author is supported by Grant-in-Aid for Scientific Research no. 22540175 from the Japan Society for the Promotion of Science.

\section{References}

[1] J.-L. Lions and G. Stampacchia, "Variational inequalities," Communications on Pure and Applied Mathematics, vol. 20, pp. 493519, 1967.

[2] J.-B. Baillon and G. Haddad, "Quelques propriétés des opérateurs angle-bornés et $n$-cycliquement monotones," Israel Journal of Mathematics, vol. 26, no. 2, pp. 137-150, 1977.
[3] J. C. Dunn, "Convexity, monotonicity, and gradient processes in Hilbert space," Journal of Mathematical Analysis and Applications, vol. 53, no. 1, pp. 145-158, 1976.

[4] F. Liu and M. Z. Nashed, "Regularization of nonlinear illposed variational inequalities and convergence rates," SetValued Analysis, vol. 6, no. 4, pp. 313-344, 1998.

[5] K. Nakajo and W. Takahashi, "Strong and weak convergence theorems by an improved splitting method," Communications on Applied Nonlinear Analysis, vol. 9, no. 2, pp. 99-107, 2002.

[6] Y. Haugazeau, Sur les inéquations variationnelles et la minimisation de fonctionnelles convexes [Ph.D. thesis], Université de Paris, Paris, France, 1968.

[7] M. V. Solodov and B. F. Svaiter, "Forcing strong convergence of proximal point iterations in a Hilbert space," Mathematical Programming, vol. 87, no. 1, pp. 189-202, 2000.

[8] H. H. Bauschke and P. L. Combettes, "A weak-to-strong convergence principle for Fejér-monotone methods in Hilbert spaces," Mathematics of Operations Research, vol. 26, no. 2, pp. 248-264, 2001.

[9] K. Nakajo and W. Takahashi, "Strong convergence theorems for nonexpansive mappings and nonexpansive semigroups," Journal of Mathematical Analysis and Applications, vol. 279, no. 2, pp. 372-379, 2003.

[10] S. Kamimura and W. Takahashi, "Strong convergence of a proximal-type algorithm in a Banach space," SIAM Journal on Optimization, vol. 13, no. 3, pp. 938-945, 2002.

[11] S. Ohsawa and W. Takahashi, "Strong convergence theorems for resolvents of maximal monotone operators in Banach spaces," Archiv der Mathematik, vol. 81, no. 4, pp. 439-445, 2003.

[12] F. Kohsaka and W. Takahashi, "Iterative scheme for finding a common point of infinitely many convex sets in a Banach space," Journal of Nonlinear and Convex Analysis, vol. 5, no. 3, pp. 407414, 2004.

[13] S. Matsushita and W. Takahashi, "A strong convergence theorem for relatively nonexpansive mappings in a Banach space," Journal of Approximation Theory, vol. 134, no. 2, pp. 257-266, 2005.

[14] S. Matsushita, K. Nakajo, and W. Takahashi, "Strong convergence theorems obtained by a generalized projections hybrid method for families of mappings in Banach spaces," Nonlinear Analysis: Theory, Methods \& Applications, vol. 73, no. 6, pp. 1466-1480, 2010.

[15] K. Nakajo, K. Shimoji, and W. Takahashi, "Strong convergence theorems by the hybrid method for families of mappings in Banach spaces," Nonlinear Analysis: Theory, Methods \& Applications, vol. 71, no. 3-4, pp. 812-818, 2009.

[16] H. Iiduka, W. Takahashi, and M. Toyoda, "Approximation of solutions of variational inequalities for monotone mappings," Panamerican Mathematical Journal, vol. 14, no. 2, pp. 49-61, 2004.

[17] K. Nakajo, K. Shimoji, and W. Takahashi, "Strong convergence theorems by the hybrid method for families of nonexpansive mappings in Hilbert spaces," Taiwanese Journal of Mathematics, vol. 10, no. 2, pp. 339-360, 2006.

[18] K. Nakajo, K. Shimoji, and W. Takahashi, "On strong convergence by the hybrid method for families of mappings in Hilbert spaces," Nonlinear Analysis: Theory, Methods \& Applications, vol. 71, no. 1-2, pp. 112-119, 2009.

[19] H. Iiduka and W. Takahashi, "Strong convergence studied by a hybrid type method for monotone operators in a Banach space," Nonlinear Analysis: Theory, Methods \& Applications, vol. 68, no. 12, pp. 3679-3688, 2008. 
[20] W. Takahashi, Nonlinear Functional Analysis, Fixed Point Theory and Its applications, Yokohama Publishers, Yokohama, Japan, 2000.

[21] W. Takahashi, Convex Analysis and Approximation of Fixed Points, vol. 2, Yokohama Publishers, Yokohama, Japan, 2000 (Japanese).

[22] H. K. Xu, "Inequalities in Banach spaces with applications," Nonlinear Analysis: Theory, Methods \& Applications, vol. 16, no. 12, pp. 1127-1138, 1991.

[23] C. Zălinescu, "On uniformly convex functions," Journal of Mathematical Analysis and Applications, vol. 95, no. 2, pp. 344374, 1983.

[24] Y. I. Alber, "Metric and generalized projection operators in Banach spaces: properties and applications," in Theory and Applications of Nonlinear Operators of Accretive and Monotone Type, vol. 178 of Lecture Notes in Pure and Applied Mathematics, pp. 15-50, Dekker, New York, NY, USA, 1996.

[25] Y. I. Alber and S. Reich, "An iterative method for solving a class of nonlinear operator equations in Banach spaces," Panamerican Mathematical Journal, vol. 4, no. 2, pp. 39-54, 1994.

[26] K. Goebel and S. Reich, Uniform Convexity, Hyperbolic Geometry, and Nonexpansive Mappings, vol. 83 of Monographs and Textbooks in Pure and Applied Mathematics, Marcel Dekker, New York, NY, USA, 1984.

[27] R. T. Rockafellar, "On the maximality of sums of nonlinear monotone operators," Transactions of the American Mathematical Society, vol. 149, pp. 75-88, 1970.

[28] F. E. Browder, "Nonlinear maximal monotone operators in Banach space," Mathematische Annalen, vol. 175, pp. 89-113, 1968.

[29] V. Barbu, Nonlinear Semigroups and Differential Equations in Banach Spaces, Editura Academiei Republicii Socialiste România, Bucharest, Romania, 1976.

[30] K. Nakajo, K. Shimoji, and W. Takahashi, "Approximations for nonlinear mappings by the hybrid method in Hilbert spaces," Nonlinear Analysis: Theory, Methods \& Applications, vol. 74, no. 18, pp. 7025-7032, 2011.

[31] R. T. Rockafellar, "Characterization of the subdifferentials of convex functions," Pacific Journal of Mathematics, vol. 17, pp. 497-510, 1966.

[32] R. T. Rockafellar, "On the maximal monotonicity of subdifferential mappings," Pacific Journal of Mathematics, vol. 33, pp. 209216, 1970.

[33] L. M. Bregman, "The method of successive projection for nding a common point of convex sets," Soviet Mathematics. Doklady, vol. 6, pp. 688-692, 1965.

[34] G. Crombez, "Image recovery by convex combinations of projections," Journal of Mathematical Analysis and Applications, vol. 155, no. 2, pp. 413-419, 1991. 


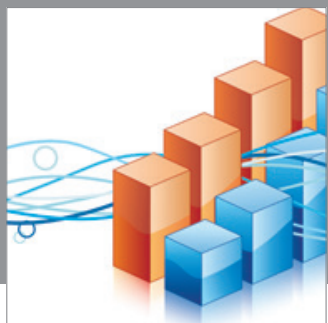

Advances in

Operations Research

mansans

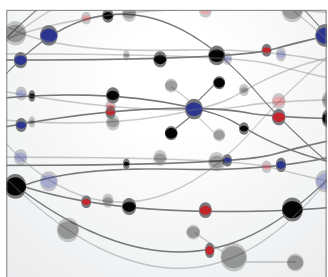

The Scientific World Journal
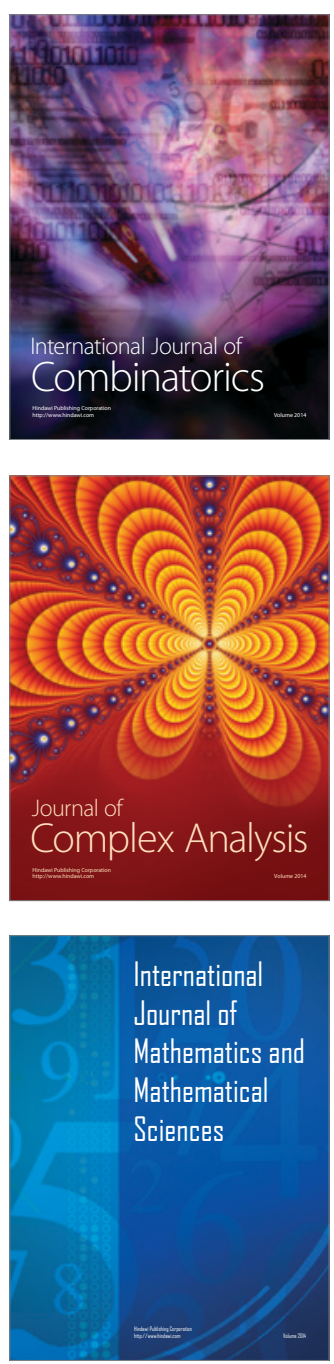
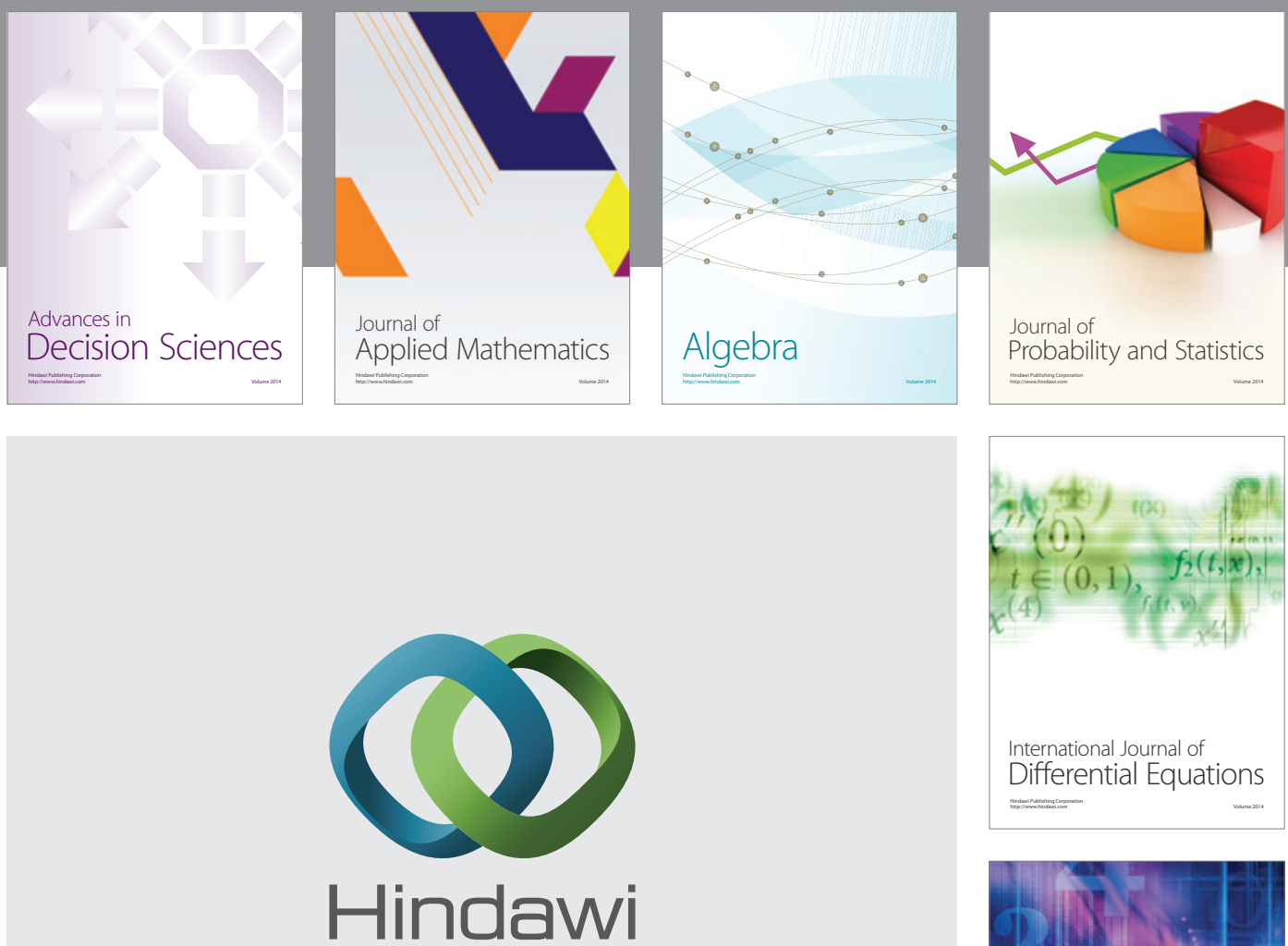

Submit your manuscripts at http://www.hindawi.com
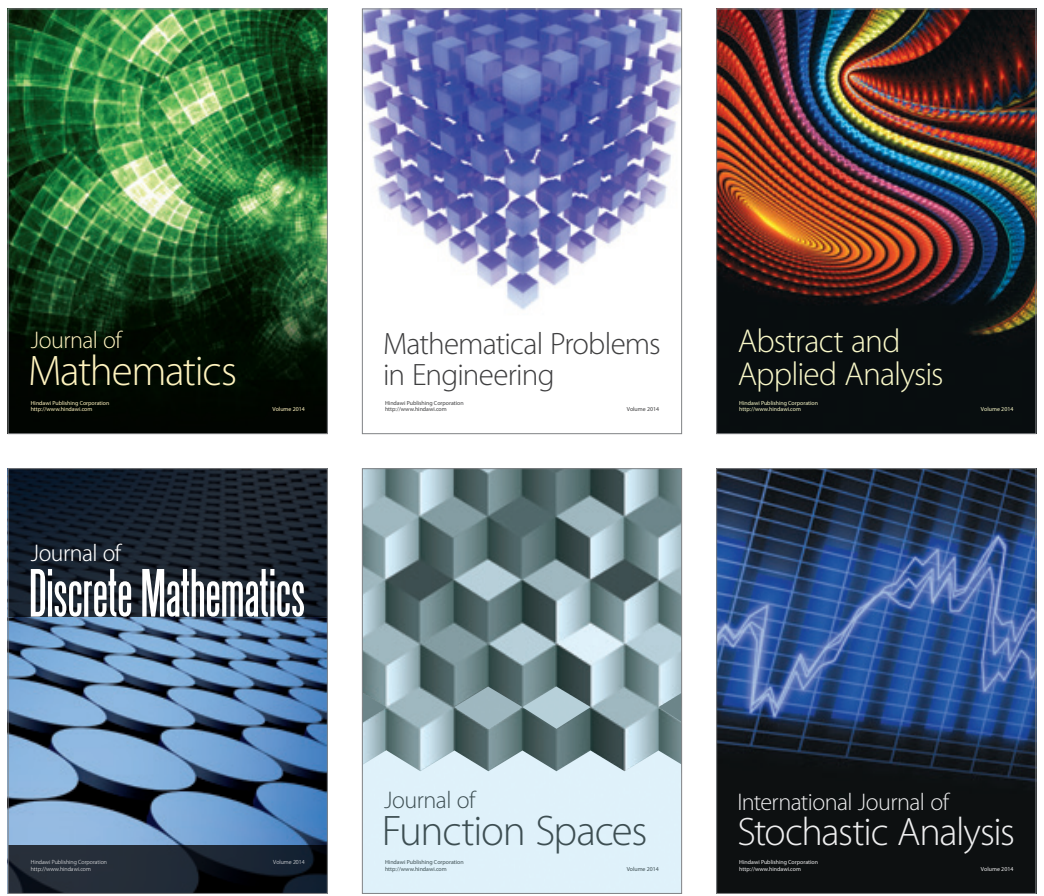

Journal of

Function Spaces

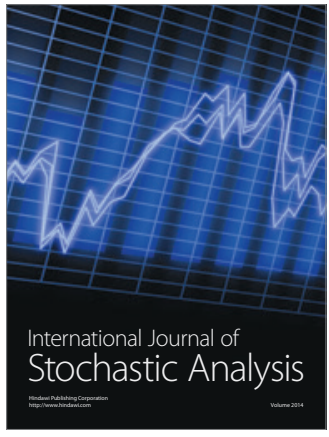

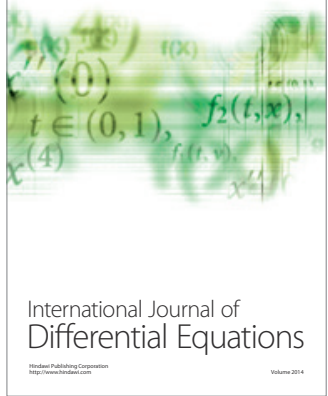
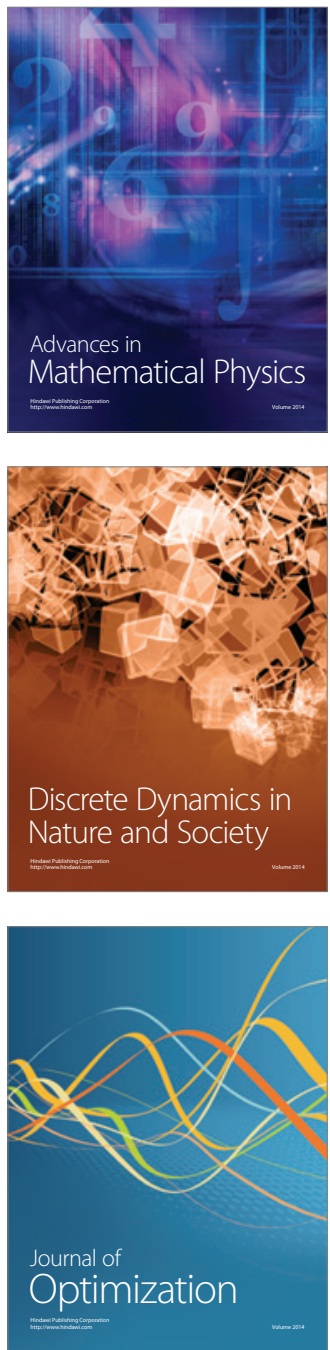